\title{
$\{1\}$ BIOENG
}

\section{PRODUÇÃO DE MILHO EM DIFERENTES PROFUNDIDADES DE PLANTIO}

\author{
A. P. F. Silva ${ }^{1}$, D. J. da Costa ${ }^{1}$, D. L. C. Vicente $^{1}$, A. A. da Silva ${ }^{1^{*}}$,
} C. S. Pereira ${ }^{2}$

\author{
${ }^{1}$ UNIFOR-MG - Centro Universitário de Formiga, Formiga, MG, Brasil \\ ${ }^{2}$ UFMT - Universidade Federal de Mato Grosso, Sinop, MT, Brasil
}

Article history: Received 05 November 2019; Received in revised form 15 November 2019; Accepted 20 November 2019; Available online 05 December 2019.

\begin{abstract}
RESUMO
O milho (Zea mays L.) é um dos cereais mais utilizados e relevantes, devido às suas propriedades nutricionais, composição química e diversidade de utilização, tanto na alimentação humana quanto animal. Com as constantes inovações no setor agropecuário, buscando-se uma melhor produção e redução de custos, surge um crescente interesse por prover alternativas que maximizem os resultados produtivos do setor. Nesse contexto, o objetivo deste experimento foi analisar os resultados e variações da cultura do milho, em relação ao seu desenvolvimento e produtividade, obtida em diferentes profundidades de plantio. $\mathrm{O}$ experimento foi implantado em condições de campo, utilizando o delineamento em blocos casualizados, constituídos de 4 tratamentos e 4 repetições, em 4 linhas, espaçadas a 0,55 metros entre linhas e 16 metros de comprimento, totalizando $35,2 \mathrm{~m}^{2}$ por parcela. Foram empregados quatro tratamentos: $1,2,3$ e 4 , definidos a $1 \mathrm{~cm}, 3 \mathrm{~cm}, 5 \mathrm{~cm}$ e $7 \mathrm{~cm}$ respectivamente. Foram avaliados os seguintes parâmetros: índice de velocidade de emergência, diâmetro de colmo, altura da planta e produtividade. Com este estudo, observouse que o índice de velocidade de emergência sofre influência da profundidade de semeadura, quanto menor, mais rápido a planta emerge. Em relação à produtividade, o resultado foi inverso ao IVE, ou seja, quanto maior a profundidade, melhor o índice produtivo da cultura analisada, ratificado pelo melhor índice de diâmetro do colmo, altura e produção.
\end{abstract}

Palavras-chave: Cultura do milho; influência; profundidade; produção.

\section{CORN PRODUCTION AT DIFFERENT PLANTING DEPTHS.}

\begin{abstract}
Corn (Zea mays L.) is one of the most used and relevant cereals due to its nutritional properties, chemical composition and diversity of use, both in human and animal food. With the constant innovations in the agricultural sector, seeking better production and cost reduction, a growing interest arises in providing alternatives that maximize the productive results of the sector. In this context, the objective of this experiment was to analyze the results and variations of corn crop, in relation to its development and productivity, obtained at different planting depths. The experiment was implanted under field conditions, using the design in randomized blocks, consisting of 4 treatments and 4 replications, in 4 lines, spaced at 0.55 meters between lines and 16 meters in length, totaling $35.2 \mathrm{~m}^{2}$ per plot. Four treatments were used: 1, 2, 3 and 4, defined at $1 \mathrm{~cm}, 3 \mathrm{~cm}, 5 \mathrm{~cm}$ and $7 \mathrm{~cm}$ respectively. The following parameters were evaluated: emergence speed index, stem diameter, plant height and
\end{abstract}

\footnotetext{
adrianoas@msn.com
} 
productivity. With this study, it was observed that the emergence velocity index is influenced by sowing depth, the lower the plant emerges. Regarding productivity, the result was inverse to the IVE, that is, the higher the depth, the better the productive index of the analyzed crop, ratified by the best rate of stem diameter, height and production.

Keywords: Corn culture; influence; depth; Production.

\section{INTRODUÇÃO}

O milho possui a seguinte classificação: Zea mays L., família Poaceae. Historicamente, há registros que demonstram que as primeiras culturas surgiram em pequenas ilhas próximas ao litoral do México, no continente Americano. Desde o primeiro registro, pertinente ao processo de colonização americana até a contemporaneidade, observa-se que a respectiva cultura foi acompanhando a evolução do homem e de suas técnicas produtivas (GALVÃO; BORÉM; PIMENTAL, 2017).

Considerado como um produto versátil, de múltiplas aplicabilidades, o milho é a base para a obtenção de insumos para o segmento produtivo, em especial, para a suinocultura, avicultura e bovinocultura leiteira, tanto na forma de farelo, de rações ou de silagem. Na alimentação humana, o milho é comumente empregado na forma in natura, como milho verde, e na forma de subprodutos, como pão, farinha, massas, óleo (CANTARELLA, 1993) e também na produção de etanol (ALVES, 2007).

Sobre suas características botânicas, o milho é uma gramínea anual, com altura entre 1,70 e 2,50 m no florescimento. Com possibilidade de cultivo desde o nível do mar até $3.600 \mathrm{~m}$ de altitude, cuja temperatura se apresente entre uma média noturna acima de $12,8^{\circ} \mathrm{C}$ e média diurna superior a $19^{\circ}$ C. Acerca de suas necessidades hídricas, o consumo médio ideal é entre 500 a $800 \mathrm{~mm}$ de lâmina d'água, desde a semeadura até o ponto de maturação fisiológica dos grãos. Em relação às fases mais susceptíveis ao déficit hídrico, observam-se a inicial floral e o desenvolvimento da inflorescência, além do período de fertilização e enchimento dos grãos (DARÓS, 2007).
A formação de grãos na cultura do milho depende também da translocação de açúcares e de $\mathrm{N}$ de órgãos vegetativos, sendo que o rendimento de grãos está diretamente relacionado com a área foliar fotossinteticamente ativa da planta. Folhas com adequados teores de $\mathrm{N}$ têm maior capacidade de assimilar $\mathrm{CO}_{2}$ e sintetizar carboidratos durante a fotossíntese, resultando em maior acúmulo de massa seca, possibilitando maior rendimento de grãos (BARROS NETO, 2008).

Acerca dos tipos de solo, requisitos importantes e imprescindíveis devem ser observados. Os solos de textura média, com teores de argila em torno de 30-35\%, ou mesmo argilosos, com boa estrutura, como os latossolos, que possibilitam drenagem adequada, apresentam boa capacidade de retenção de água e de nutrientes disponíveis às plantas, são os mais recomendados para a cultura do milho (MATOS, 2007).

$\mathrm{O}$ autor supracitado complementa que os solos arenosos (teor de argila inferior a $15 \%$ ) devem ser evitados, devido à sua baixa capacidade de retenção de água e nutrientes disponíveis às plantas. Alguns solos com tipo de argila expansiva (tipo montmorilonita) podem apresentar forte agregação, prejudicando as condições de permeabilidade e a livre penetração do sistema radicular, e devem também ser evitados.

Em relação à profundidade de semeadura, Cruz, Pereira Filho e Albuquerque Filho (2018) afirmam que ela está condicionada a questões como temperatura do solo, umidade e tipo do solo. Assim, o tipo de solo determina a profundidade mais viável. Geralmente, a profundidade ideal aumenta, na medida em que o solo se torna mais leve, assim, as 
sementes podem ser colocadas entre $5 \mathrm{~cm}$ a $7 \mathrm{~cm}$ em solos leves ou arenosos.

A densidade de plantio, ou estande, que representa o número de plantas por unidade de área também influencia sistematicamente no rendimento de uma lavoura de milho. Observa-se que pequenas variações na densidade têm reflexo no rendimento final da cultura (CRUZ; PEREIRA FILHO; ALBUQUERQUE, 2018).

$\mathrm{O}$ conhecimento dos fatores que influenciam o desenvolvimento satisfatório da cultura de milho é muito importante para a obtenção dos melhores índices produtivos.

De acordo com Mendes (2019), os dados fornecidos pela Companhia Nacional de Abastecimento (CONAB) ratificam que a safra de milho brasileira 2018/19 alcançará a marca histórica de aproximadamente 240,7 milhões de

\section{MATERIAL E MÉTODO}

O trabalho foi conduzido e realizado em uma Fazenda denominada Rincãozinho, situada no município de Piumhi, mesorregião Oeste do Estado de Minas Gerais, com as seguintes coordenadas geográficas: 20²1'40”S 46 03'39' W. O referido município se localiza em uma área de $793 \mathrm{~m}$ de altitude. Clima do tipo Cwa, segundo a classificação Koppen (SÁ JÚNIOR, 2009). Temperatura média de $22^{\circ} \mathrm{C}$ e vegetação típica de cerrado.

Foram analisados diferentes índices de profundidades de plantio de milho do tipo híbrido Nidera NS90PRO.

$\mathrm{O}$ delineamento utilizado foi em bloco casualizado, constituídos de 4 tratamentos em 4 blocos, em que cada parcela experimental foi constituída de quatro linhas, espaçadas de $0,55 \mathrm{~m}$ entre linhas e $16 \mathrm{~m}$ de comprimento. Totalizando $35,2 \mathrm{~m}^{2}$ por parcela. Em cada tratamento, avaliou-se 4 (quatro) variáveis: índice de velocidade de emergência (IVE), diâmetro do colmo, altura e produção.

Os tratamentos deste experimento foram realizados por plantio direto, toneladas, que representa um percentual de $5,7 \%$ a mais que a safra anterior. Além disso, o Brasil ocupa a $2^{\mathrm{a}}$ posição como maior exportador dessa commodity.

Em função da expressividade desses números, faz-se necessário que sejam intensificados experimentos a fim de responder a todos os questionamentos e inferências sobre as vulnerabilidades e potencialidades que de alguma forma corroborem para assegurar patamares produtivos ainda maiores, permitindo que o Brasil ocupe sempre uma posição que faça jus às características favoráveis que o país possui no contexto internacional em relação à produção de grãos.

A partir das proposições apresentadas foi definido o objetivo deste estudo que se propôs a avaliar o desenvolvimento da cultura de milho, por meio do plantio em diferentes profundidades.

realizado no dia 16 de março de 2019 , por meio de plantadeira TATU PST PLUS pantográfica de 4 (quatro) linhas de plantio. Vale destacar que a plantadeira possui 6 (seis) linhas, porém as linhas externas foram descartadas.

A regulagem da plantadeira foi feita para 3,2 sementes por metro, com o espaçamento de $55 \mathrm{~cm}$ entre linhas. Em relação à regulagem do adubo, foi 11 gramas por metro. $\mathrm{O}$ adubo empregado foi Polyblen.

Os tratamentos se diferiram em relação à profundidade adotada, sendo trabalhadas as seguintes metragens: primeiro tratamento foi semeado a $1 \mathrm{~cm}$ de profundidade; o segundo a $3 \mathrm{~cm}$; o terceiro a $5 \mathrm{~cm}$; e o quarto a $7 \mathrm{~cm}$.

A primeira variável, que se refere ao IVE que foi analisado de forma sistemática contínua do $3^{\circ}$ ao $13^{\circ}$ dia.

Assim, após 3 (três) dias do plantio, houve a primeira contagem da emergência das plântulas de milho. Observou-se que o tratamento com a menor profundidade emergiu primeiro que os demais. 
No $25^{\circ}$ dia, foi efetuada a capina mecanizada com emprego de Atrazina e Soberan. Simultaneamente, a realização da capina foi feita a aplicação de inseticida Lannate e Nomolt 150, para se evitar a infestação de pragas no experimento.

A avaliação das variáveis: diâmetro e altura, foi realizada no $50^{\circ}$ dia. A altura das plantas foi medida da superfície do solo até a base da última folha com auxílio de fita métrica. $\mathrm{O}$ diâmetro foi medido com auxílio de paquímetro a partir do entrenó do colmo do milho.

A última fase deste experimento ocorreu no dia 14 de agosto de 2019, em que se analisou a última variável, ou seja, a produção. Nesse dia, foi realizada a colheita manual. Todo o milho do experimento foi debulhado manualmente. Posteriormente, foi feita a separação de cada produção por tratamento em cada repetição.

O solo utilizado neste experimento foi um latossolo vermelho eutrófico. Nesse local, que foi realizado o experimento, normalmente, é feito o plantio e milho há aproximadamente 4 anos. No entanto, em 2018, a área foi destinada ao plantio de soja, no intuito de fazer a rotação de cultura, a fim de manter os talhões da lavoura em equilíbrio.
No dia 22 de março de 2019, uma amostra do respectivo solo foi submetida à análise por meio da Agrolab Análises Agrícolas. Os resultados foram gerados em 29 de março de 2019.

Vale destacar que o milho é uma cultura que se adapta aos diferentes tipos de solos. No entanto, os solos profundos são considerados mais adequados. Os solos de textura intermediária deverão ser complementados, no intuito de possibilitar o armazenamento adequado de água e nutrientes, bem como, uma permeabilidade condizente com as necessidades de trocas gasosas e movimento da água. Solos com altos índices de compactação e drenagem insuficiente prejudicam o desenvolvimento da cultura do milho (FORNASIERI FILHO, 2007).

De acordo com os resultados da análise do solo deste experimento, apresentados na Tabela 1, é possível verificar que as condições do solo são favoráveis ao desenvolvimento da respectiva cultura. Para a correção e adubação do solo foram seguidas as recomendações referentes à quinta aproximação da Comissão de Fertilidade do Solo do Estado de Minas Gerais (CFSMG) (RIBEIRO; GUIMARÃES; ALVAREZ, 1999).

Tabela 1 - Laudo de análise do solo

\begin{tabular}{|c|c|c|}
\hline ELEMENTO QUÍMICO & UNIDADE DE MEDIDA & RESULTADO \\
\hline $\mathrm{pH} \mathrm{CaCl} 2$ & $1: 2,5$ & 6,5 \\
\hline $\mathrm{P} \mathrm{Meh}^{-1}$ & $\mathrm{mg} \mathrm{dm}^{-3}$ & 22,8 \\
\hline P rem. & $\mathrm{mg} \mathrm{dm} \mathrm{dm}^{-3}$ & 19,4 \\
\hline K Mehlich & $\mathrm{mg} \mathrm{dm}^{-3}$ & 188,82 \\
\hline $\mathrm{S}-\mathrm{SO}_{4}^{-2}$ & $\mathrm{mg} \mathrm{dm}^{-3}$ & 12 \\
\hline $\mathrm{Ca}^{2+}$ & mmolc $\mathrm{dm}^{-3}$ & 60,0 \\
\hline $\mathrm{Mg}^{2+}$ & mmolc $\mathrm{dm}^{-3}$ & 15,0 \\
\hline $\mathrm{Al}^{3+}$ & mmolc $\mathrm{dm}^{-3}$ & 0,00 \\
\hline $\mathrm{H}^{+} \mathrm{Al}$ & mmolc $\mathrm{dm}^{-3}$ & 11,00 \\
\hline MO & $\mathrm{g} / \mathrm{kg}$ & 26,9 \\
\hline $\mathrm{CO}$ & $\mathrm{g} / \mathrm{kg}$ & 15,6 \\
\hline SB & mmolc dm ${ }^{-3}$ & 79,80 \\
\hline $\mathrm{T}$ & mmolc $\mathrm{dm}^{-3}$ & 79,80 \\
\hline CTC & mmolc dm $\mathrm{dm}^{-3}$ & 90,80 \\
\hline V & $\%$ & 88 \\
\hline M & $\%$ & 0 \\
\hline
\end{tabular}

Fonte: Dados da Pesquisa, 2019.

Nota: Dados obtidos por meio da Agrolab Análises Agrícolas, 2019. 
O milho é uma cultura que tem uma exigência hídrica acentuada. $\mathrm{O}$ stress hídrico traz comprometimentos sérios à cultura, tais como, redução do vigor vegetativo, interferência na altura da planta e na fertilidade do pólen e, por conseguinte, reflexo negativo na produção final (BARROS, 2012).

Em relação à precipitação pluviométrica, durante o período do desenvolvimento deste experimento, foram captados os milímetros de chuva, sintetizados por meio do Gráfico 1. É possível notar que houve uma maior precipitação pluviométrica, no mês de março de 2019, havendo uma diminuição progressiva nos meses subsequentes, em que o mês de junho de 2019 apresentou a menor precipitação.

Gráfico 1 - Precipitação pluviométrica

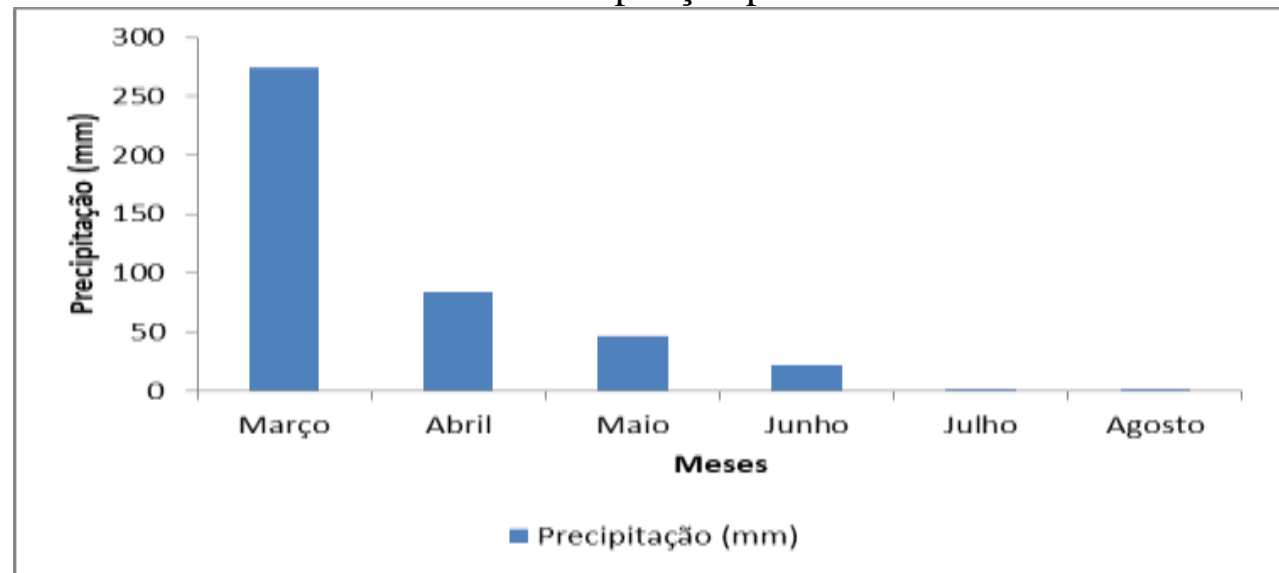

Fonte: Dados da Pesquisa, 2019.

Para analisar a variância entre as variáveis em estudo empregou-se o software SISVAR 5.0, em que foi realizado o teste Scott-Knott (1974) para

\section{RESULTADOS E DISCUSSÃO}

A Tabela 2 resume os resultados obtidos por meio da análise de variância referente ao experimento, em que se mensurou o índice de velocidade de emergência (IVE), o diâmetro do colmo, a altura de plantas e a produção de plantas de comparação entre tratamentos. A análise de variância estabelece avaliar as variações analisadas, adotando-se o nível de significância de $5 \%$.

Tabela 2 - Resumo da análise de variância

\begin{tabular}{l|c|c|c|c|c}
\hline \multicolumn{1}{c}{ FV } & GL & QUE & DIÂAMETRO & ALTURA & PRODUÇÃO \\
\hline Tratamento & 3 & 18,722340 & $11,082808^{*}$ & $0,002617^{*}$ & $1,206417^{*}$ \\
Bloco & 3 & 0,047273 & 0,228442 & 0,043317 & 0,039050 \\
Erro & 9 & 0104445 & 0,161314 & 0,000433 & 0,036867 \\
Total & 15 & & & & \\
CV $(\%)$ & & 3,84 & 1,60 & 0,97 & 7,50 \\
\hline
\end{tabular}

Fonte: Dados da Pesquisa, 2019.

milho submetidas a diferentes profundidades de semeadura: $1 \mathrm{~cm}, 3 \mathrm{~cm}$, $5 \mathrm{~cm}$ e $7 \mathrm{~cm}$ respectivamente.

Pelos respectivos resultados, observa-se que todas as variáveis foram significativas a $5 \%$ de probabilidade.

Nota: *Significativo a 5\% pelo Teste $\mathrm{F}$. 
A temperatura influencia no enchimento de grãos. De acordo com um experimento desenvolvido por Cruz et al. (2006), o milho obteve maior produção de matéria seca e maior rendimento de grãos a uma temperatura de $21^{\circ} \mathrm{C}$.

Barros (2012) ainda complementa que na fase de germinação e emergência, a temperatura ideal deve ficar em torno de $25^{\circ} \mathrm{C}$ a $30^{\circ} \mathrm{C}$. No período de florescimento e maturação, temperaturas acima de $26^{\circ} \mathrm{C}$ potencializam essa etapa. Enquanto temperaturas abaixo de $15,5^{\circ} \mathrm{C}$ são responsáveis por retardar o florescimento e a maturação.

Dentro dessas proposições, é possível intuir que o clima no qual foi submetido este experimento corroborou para os resultados obtidos, pois a temperatura média da região é de $22^{\circ} \mathrm{C}$, valor muito próximo à temperatura ideal considerada pelos autores supracitados.

A fim de mensurar a variação térmica ocorrida durante a realização deste experimento foi calculada a temperatura mensal. Os respectivos valores foram apresentados por meio do Gráfico 2 .

Gráfico 2 - Temperatura média

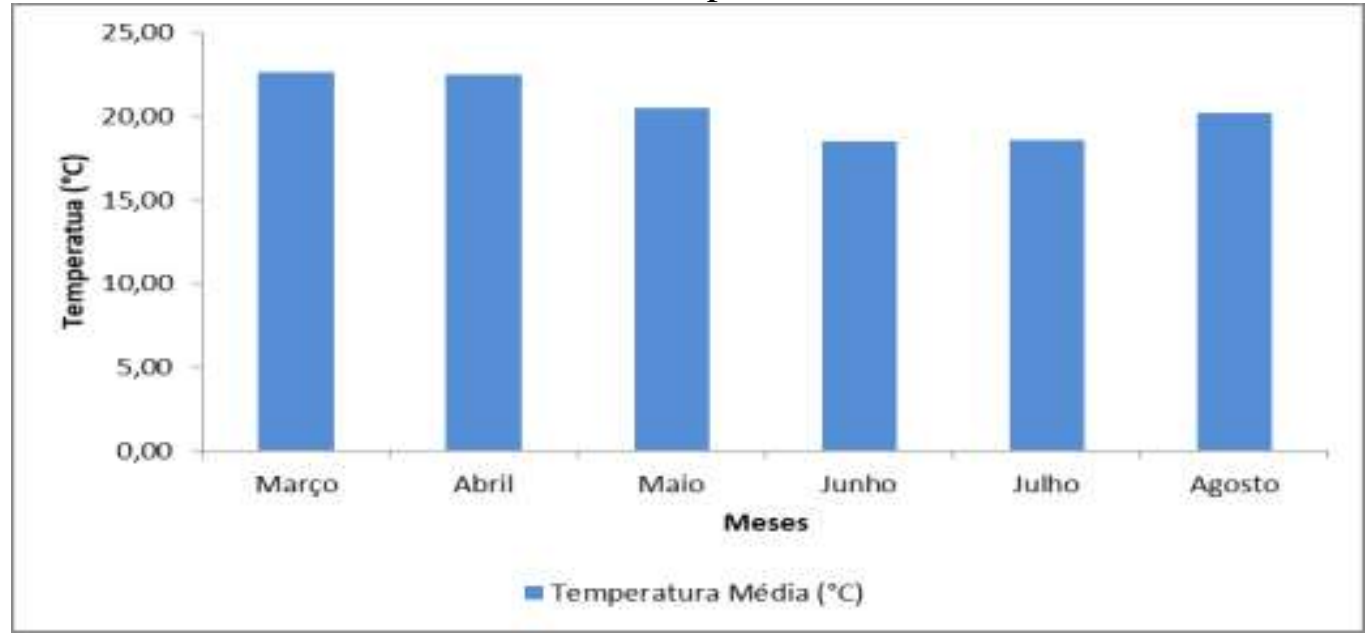

Fonte: Dados da Pesquisa, 2019.

A partir da Tabela 2, foram feitos os teste de média, em que a Tabela 3 concatena os resultados médios da avaliação do índice de velocidade de emergência (IVE), diâmetro do colmo, altura de plantas e produção de plantas de milho submetidas a diferentes profundidades de semeadura.

Tabela 3 - Resultados médios da avaliação

\begin{tabular}{c|c|c|c|c}
\hline TRATAMENTOS & IVE & $\begin{array}{c}\text { DIÂAMTRO } \\
(\mathbf{m m})\end{array}$ & $\begin{array}{c}\text { ALTURA } \\
(\mathbf{m})\end{array}$ & $\begin{array}{c}\text { PRODUÇAO } \\
(\mathbf{k g})\end{array}$ \\
\hline $1(1 \mathrm{~cm})$ & $10,87 \mathrm{a}$ & $23,05 \mathrm{c}$ & $2,13 \mathrm{~b}$ & $1,86 \mathrm{~d}$ \\
$2(3 \mathrm{~cm})$ & $9,29 \mathrm{~b}$ & $24,26 \mathrm{~b}$ & $2,14 \mathrm{~b}$ & $2,44 \mathrm{c}$ \\
$3(5 \mathrm{~cm})$ & $7,66 \mathrm{c}$ & $26,57 \mathrm{a}$ & $2,17 \mathrm{a}$ & $2,82 \mathrm{~b}$ \\
$4(7 \mathrm{~cm})$ & $5,83 \mathrm{~d}$ & $26,28 \mathrm{a}$ & $2,18 \mathrm{a}$ & $3,13 \mathrm{a}$ \\
\hline
\end{tabular}

Fonte: Dados da Pesquisa, 2019.

Nota: as médias seguidas de letras minúsculas na coluna não diferem entre si pelo teste de Scott-Knott, a 5\% de probabilidade.

Ao analisar a profundidade em que foram depositadas as sementes de milho, é possível correlacioná-las com o índice de energia consumido pela planta ao emergir, ou seja, quanto mais profundo, mais lento 
será o IVE dessa planta (NAFZIGER et al., 1991).

Neste estudo, foi constatada situação semelhante, pois o IVE das plantas submetidas a menores profundidades emergiram primeiro, ou seja, quanto maior a profundidade, maior a energia consumida pela planta e, consequentemente, maior o tempo gasto para emergir.

Assim, observa-se pelos resultados do IVE que o tratamento 1 (menor profundidade) proporcionou $\mathrm{o}$ maior índice, seguido pelo tratamento 2 e 3 e, em último, o tratamento 4 (maior profundidade) obteve o menor índice de velocidade de emergência, em que as respectivas profundidades foram $1 \mathrm{~cm}, 3$ $\mathrm{cm}, 5 \mathrm{~cm}$ e $7 \mathrm{~cm}$.

Sangoi et al. (2004) destacam que semeaduras profundas prejudicam a emergência e o crescimento inicial da cultura do milho em situações nas quais haja uma menor temperatura do solo na fase de estabelecimento de estande.

$\mathrm{Na}$ esteira do pensamento dos autores supracitados, Cruz et al. (2010) complementam que a profundidade de semeadura possui relação com diversos fatores intrínsecos ao solo, tais como, sua temperatura, índice de umidade e tipo específico. Nesse sentido, pressupõe-se que a profundidade escolhida deva permitir um bom contato da semente com a umidade do solo. No entanto, os diferentes tipos de solo demandam tipos diferenciados de profundidade de semeadura.

Para solos mais densos, que possuam uma drenagem deficitária, recomenda-se que a sementes sejam dispostas a uma profundidade entre 3 a $5 \mathrm{~cm}$. Por outro lado, solos mais leves ou arenosos, a profundidade deverá ser um pouco maior entre 5 e $7 \mathrm{~cm}$, no intuito de obter um melhor teor de umidade do solo (CRUZ et al., 2010).

Quando se analisam os resultados médios da avaliação do índice de velocidade de emergência (IVE) obtido por meio deste experimento e demonstrado na Tabela 2 supracitada, é possível ratificar o posicionamento de Cruz et al (2010), pois o solo respectivo ao presente experimento caracteriza-se por ser leve e a profundidade em análise teve correlação direta com os resultados obtidos.

Resultado similar foi encontrado por Gomes et al. (2016) ao concluírem que o milho Impacto Viptera 3, semeado a uma profundidade maior, a partir de $7 \mathrm{~cm}$, necessita de maior tempo para concluir a emergência total.

A segunda variável refere-se à avaliação de diâmetro do colmo. Os resultados obtidos demonstraram que os tratamentos 3 e 4 apresentaram os maiores valores e não apresentaram variação significativa entre eles, seguidos pelo tratamento 2 e, por fim, o tratamento 1 que obteve o pior resultado.

Souza et al. (2016) encontraram uma situação diferente, pois no experimento por eles desenvolvido, o diâmetro de colmo não apresentou diferença pelos tratamentos estudados, ficando em torno dos $22 \mathrm{~mm}$, ou seja, a profundidade da semeadura não interferiu no diâmetro do colmo.

É importante destacar que o diâmetro do colmo desempenha uma função vital para o desenvolvimento das plantas de milho. Ele atua de forma direta no armazenamento de fotoassimilados que na fase posterior são responsáveis pela formação dos grãos. Nesse sentido, é possível intuir que o aumento do diâmetro do colmo denota uma situação futura favorável a um índice melhor de produtividade da respectiva cultura (BRITO et al., 2014).

A análise da variação da altura das plantas demonstrou dois grupos específicos. O primeiro formado pelos tratamentos 3 e 4 que alcançaram os melhores índices e o segundo constituído pelos tratamentos 1 e 2 que apresentaram as menores dimensões em valores de altura. Nesse sentido, quanto maior a profundidade, maior a altura da planta.

Souza et al. (2016) obtiveram um resultado próximo, pois a altura das plantas de milho variaram em função da profundidade de semeadura, em que os menores valores estavam relacionados com 
as plantas semeadas em menores profundidades.

No entanto, em outro experimento, Gomes et al. (2016) avaliaram quatro níveis diferentes de profundidade: $3,5,7$ e $10 \mathrm{~cm}$. Os resultados demonstraram que a melhoria no desenvolvimento inicial, descrita por meio do aumento em altura e comprimento de raízes não foi percebida em função dos níveis de profundidade avaliados, mas decorreram em função do tratamento direcionado às sementes empregadas no respectivo experimento.

A última variável mensurou a produção. Observa-se que os resultados foram proporcionais, quanto maior a

\section{CONCLUSÕES}

Nas condições submetidas ao experimento, a maior profundidade foi responsável pelos melhores índices produtivos avaliados, em que se observou

\section{REFERÊNCIAS BIBLIOGRÁFICAS}

ALVES, G. C. Efeito da inoculação de bactérias Diazotróficas dos gêneros Herbaspirillum e Bulkhorderia em genótipos de milho. 2007. 65 p. Dissertação (Mestrado em Agronomia) Universidade Federal Rural do Rio de Janeiro. Seropédica, RJ. Disponível em $<$ http://bdtd.ufrrj.br//tde_busca/arquivo.ph p? codArquivo $=909>$ Acesso em: 15 set. de 2019.

BARROS NETO, C. R. de. Efeito do nitrogênio e da inoculação de sementes com Azospirillum brasiliense no rendimento de grãos de milho. 2008. 29 p. Trabalho de Conclusão de Curso (Graduação em Agronomia) - Setor de Ciências Agrárias e de Tecnologia, Universidade Estadual de Ponta Grossa, Paraná.

BARROS, N. A cultura do milho. Agronomia digital, 2012. Disponível em: <https://agronomiadigital.com.br/2012/12/ a-cultura-do-milho.pdf.> Acesso em: 2 nov. 2019. profundidade maior a produção. Assim, o tratamento mais profundo (4) obteve o maior peso de grãos de milho, seguido pelos tratamentos 3,2 e, por fim, o tratamento 1 que apresentou o menor peso dentre os demais.

Um resultado próximo à conclusão obtida neste experimento, foi encontrada também por Souza et al. (2016), que avaliaram a cultura de milho em diferentes profundidades. Assim, no respectivo experimento, os piores resultados de produtividade foram encontrados nos tratamentos em que as sementes foram colocadas nas menores profundidades.

um maior diâmetro do colmo, uma maior altura da planta e um maior peso dos grãos de milho.

BRITO, C. F. B. et al. Desenvolvimento inicial do milho submetido a doses de esterco bovino. Revista Verde, v. 9, n. 3, p. $244-250,2014$.

\section{CANTARELLA, H. Calagem e adubação} do milho. In: BULL, L.T.; CANTARELLA, H. Cultura do milho: Fatores que afetam a produtividade. Piracicaba: Potafos, 1993. cap. 6, p. 147196.

CRUZ, J. C. et al. Cultivo do milho. Sistemas de Produção, n.2, versão eletrônica, 6 ed., set., 2010, Embrapa Milho e Sorgo. Disponível em: $<$ https://ainfo.cnptia.embrapa.br/digital/bit stream/item/27037/1/Plantio.pdf>. Acesso em: 31 out. 2019.

Manejo da cultura de milho. Circular Técnica 87. Sete Lagoas: Embrapa, 2006. Disponível em: <https://ainfo.cnptia.embrapa.br/digital/bit stream/CNPMS/19631/1/Circ_87.pdf>. Acesso em: 31 out. 2019. 
CRUZ, J. C.; PEREIRA FILHO, I. A.; ALBURQUERQUE FILHO, M. R. Espaçamento e densidade. AGEITEC. Agência Embrapa de Informação Tecnológica, 2018. Disponível em: <https://www.agencia.cnptia.embrapa.br/g estor/milho/arvore/CONTAG01_49_16820 0511159.html>. Acesso em: 1 nov. 2019.

DARÓS, R. Anuário brasileiro do milho. Santa Cruz do Sul: Ed. Gazeta, 2007. Disponível em <Anuário brasileiro do milho 2007. Santa Cruz do Sul, RS. 2007 (Ed. Gazeta Santa Cruz) 136p. il.> Acesso em 19 de ago. 2019.

FORNASIERI FILHO, D. Manual da cultura do milho. Jaboticabal: Funep, 2007.

GALVÃO, J. C. C.; BORÉM, A.; PIMENTEL, M. A. Milho: do plantio à colheita. Viçosa: UFV, 2017.

GOMES, M. T. et al. Germinação de sementes de milho com e sem aplicação de acetato de zinco em diferentes profundidade de semeadura. Revista Ciências Exatas e da Terra e Ciências Agrárias, v. 11, n. 1, p. 33-41, jan./jul., $2016 . \quad$ Disponível em: <http://revista2.grupointegrado.br/revista/i ndex.php/campodigital/article/view/2069/7 93>. Acesso em: 2 nov. 2019.

MATOS, E. H. da S. F. Dossiê técnico: cultivo do milho verde. Centro de Apoio ao Desenvolvimento Tecnológico, 2007. Disponível em: <https://www.agrolink.com.br/downloads/ Cultivo\%20do\%20Milho\%20Verde.pdf $>$. Acesso em 15 set. 2019.
MENDES, L. G. Todas as perspectivas para produção de milho 2019 e seu mercado de preços. Lavoura 10. Aegro, jul., 2019. Disponível em: $<$ https://www.aegro.com.br/producao-demilho-2019/>. Acesso em: 1 nov. 2019.

NAFZIGER, E. D. et al. Milho: resposta desigual de emergência. Revista Science, Madison, v. 31, n. 3, p. 811-15, 1991.

RIBEIRO, A. C.; GUIMARÃES, P. T. G.; ALVAREZ V. V. H. Recomendação para o uso de corretivos e fertilizantes em Minas Gerais: 5a aproximação. Viçosa, MG: Comissão de Fertilidade do Solo do Estado de Minas Gerais, 1999.

SÁ JÚNIOR, A. de. Aplicação da classificação de Koppen para o zoneamento climático do Estado de Minas Gerais. 2009. 101 f. Dissertação (Mestrado) - Cursos de Engenharia Agrícola / Engenharia de Água e Solo, Universidade Federal de Lavras, UFLA, Lavras, 2009.

SANGOI, L. et al. Tamanho de semente, profundidade de semeadura e crescimento inicial do milho em duas épocas de semeadura. Revista Brasileira de Milho e Sorgo, v. 3, n. 3, p. 370-380, 2004. Disponível em: <http://rbms.cnpms.embrapa.br/index.php/ ojs/article/view/115/pdf_380>. Acesso em: 2 nov. 2019.

SOUZA, S. F. G. de. et al. Avaliação da cultura de milho semeada em diferentes profundidades. Energ. Agric., Botucatu, vol. 31, n.2, p.148-153, abril-junho, 2016. Disponível em: <http://200.145.140.50/index.php/energia/a rticle/download/2252/1471>. Acesso em: 1 nov. 2019. 